\title{
Prediksi Sedimentasi Kali Mas Surabaya
}

\author{
Ismail Saud \\ Staft Pengajar Program Studi D-III Teknik Sipil FTSP - ITS \\ email: ismail@ce.its.ac.id
}

\begin{abstract}
ABSTRAK
Kali Surabaya merupakan sungai yang sangat potensial sebagai pengendali banjir dan transportasi air. Perubahan penggunaan lahan di Daerah Aliran Sungai (DAS) Brantas bagian hulu berdampak pada proses angkutan sediment sepanjang Kali Mas. Kondisi angkutan sedimen dari tahun ke tahun semakin meningkat, sehingga semakin memperkecil bank full capacity karena banyaknya pengendapan di sepanj ang Kali Mas. Proses utama yang menyebabkan terbawanya sediment oleh aliran sungai adalah proses erosi. Erosi yang terjadi karena turunnya air hujan, yang bukan hanya membantu memperbanyak kandungan sedimen juga menjadi factor hilangnya partikel tanah yang kemudian terbawa dalam aliran sungai sebagai "suspended load". Dan akan mengendap di Kali Mas. Untuk mengoptimalkan kapasitas penampang Kali Mas diperlukan pengerukan, Agar pelaksanaan pengerukan dapat berjalan dengan baik yang ditinjau dari waktu maupun lokasi, maka diperlukan analisis mengenai prediksi besarnya sedimentasi dan distribusinya. Dari hasil analisa di peroleh besarnya suspended load $=58.05$ $\mathrm{m} 3 /$ hari, bed load $=35.60 \mathrm{m3} /$ hari dan Total load $=913.65 \mathrm{~m} 3 /$ hari .
\end{abstract}

\section{PENDAHULUAN}

Proses sedimentasi yang terjadi pada beberapa saluran pembuang di Kota Surabaya yang bermuara / outfall di Kali Mas mempunyai pengaruh terhadap berkurangnya kapasitas tampung pada beberapa saluran tersebut. Tingginya angkutan sedimen dari erosi lahan di bagian hulu menyebabkan semakin tingginya biaya pemeliharaan untuk memperbesar daya tampung sungai dan saluran di Kota Surabaya agar dapat berfungsi secara optimal.

Selain itu kualitas air di Kalimas sangat jelek karena buangan limbah domestik dan sampah sehingga mencemari Kali Mas, hal ini sangat berpengaruh kalau Kali Mas difungsikan sebagai transportasi air terutama menimbulkan bau yang tidak sedap dan kotor.

Pemerintah pusat, Propinsi J awa Timur dan Kota Surabaya beserta jajarannya sudah berupaya secara maksimal untuk melakukan pemeliharaan berupa pengalian sedimen, namun hasilnya belum sesuai yang di harapkan. Berkaitan dengan hal tersebut diatas maka diperlukan analisis tentang prediksi sedimentasi yang diharapkan dapat memberikan hasil tentang besarnya jumlah sedimentasi akibat pengaruh degradasi pada DAS Brantas terutama pada Kali Mas di Surabaya yang nantinya dapat berguna untuk mempermudah dalam pemeliharaan sungai terutama dalam hal pengerukan sedimen yang dapat mengembalikan fungsi sungai sebagai saluran drainase kota.

\section{DASAR TEORI}

\subsection{Kapasita Angkutan Sedimen}

Kapasitas angkutan sedimen pada penampang memanjang sungai. Pada penampang memanjang sungai adalah besaran sedimen yang lewat penampang tersebut dalam satuan waktu tertentu.

Terjadinya penggerusan, pengendapan atau mengalami angkutan seimbang perlu diketahui kuantitas sedimen yang terangkut dalam proses tersebut.

Sungai disebut dalam keadaan seimbang jika kapasitas sedimen yang masuk pada suatu penampang memanjang sungai sama dengan kapasitas sedimen yang keluar dalam satuan waktu tertentu. Pengendapan terjadi 
dimana kapasitas sedimen yang masuk lebih besar dari kapasitas sedimen seimbang dalam satuan waktu. Sedangkan penggerusan adalah suatu keadaan dimana kapasitas sedimen yang masuk lebih kecil dari kapasitas sedimen seimbang dalam satuan waktu.

Gambaran berikut ini memperlihatkan keadaan suatu penampang sungai apakah akan terjadi penggerusan, pengendapan atau mengalami angkutan seimbang.

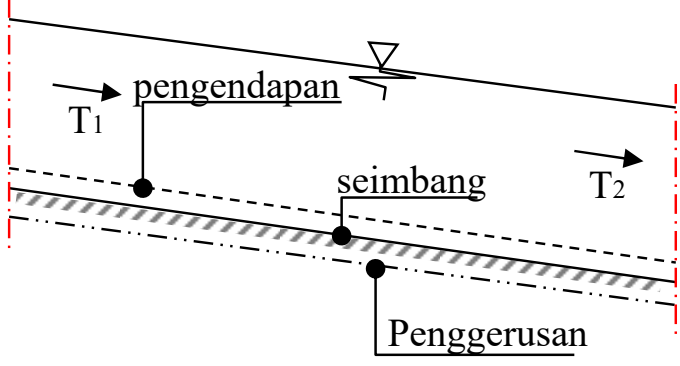

Gamb. 1 - Angkutan sedimen pada penampang memanjang sungai

Bila :

T1 < T2 maka terjadi penggerusan (degradasi)

$\mathrm{T} 1=\mathrm{T} 2$ terjadi pengangkutan sediment tetapi kondisi dasar stabil

T1 > T2 maka terjadi pengendapan (agradasi)

$\mathrm{T}=$ kapasitas pengangkutan

Adapun beberapa faktor yang menentukan angkutan sedimen (sediment transport) adalah (Mardjikoen, 1988) :
a. Sifat - sifat aliran air (flow characteristic)
b. Sifat - sifat sedimen (sediment characteristic)
c. Pengaruhnya timbal balik (interaction ))

\subsection{Angkutan sediment di sungai}

\section{a. Muatan Dasar (Bed Load Transport)}

Muatan dasar (bed load) adalah partikel yang bergerak pada dasar sungai dengan cara berguling, meluncur dan meloncat. Muatan dasar keadaanya selalu bergerak,oleh sebab itu pada sepanjang aliran dasar sungai selalu terjadi proses degradasi dan agradasi yang disebut sebagai "alterasi dasar sungai".

Beberapa formulasi untuk menghitung jumlah transportasi muatan dasar telah dikembangkan oleh beberapa peneliti dari tahun ke tahun. Formula muatan dasar ini didasarkan pada prinsip bahwa kapasitas aliran sediment transport sepanjang dasar bervariasi secara langsung dengan perbedaan antara shear stress pada partikel dasar dan shear stress (tegangan geser) kritis yang diijinkan untuk partikel yang bergerak. Beberapa formula, Meyer Peter Muller (1948) didasarkan pada hasil eksperimental yang minim. Einstein (1950) mempunyai latar belakang semi teoritis, teori statistic dan probabilitas yang dipakai sebagai dasar pembentukan formula dan eksperimental dipakai koreksi berbagai konstanta.

Formula ini sangat sesuai digunakan dalam menetukan angkutan sedimen yang bergradasi, dan kondisi aliran yang menyebabkan terbentuk konfigurasi dasar.

1. Frijlink

$$
\begin{aligned}
\mathrm{Qb}= & (\phi . \mathrm{D} 35) /(\mathrm{g} . \mu . \mathrm{R} . \mathrm{I}) 1 / 2 \\
& \text { dalam } \mathrm{m3} / \mathrm{dt} / \mathrm{m}^{\prime} \\
\Psi \quad= & (\Delta . \mathrm{D} 50) /(\mu \cdot \mathrm{R} . \mathrm{I}) \\
\mu \quad= & (\mathrm{C} / \mathrm{CD} 90) 3 / 2 \\
\mathrm{C} D 90= & 18 \log (12 \mathrm{R} / \mathrm{D} 90) \\
\mathrm{C} \quad= & 18 \log (12 \mathrm{R} / \mathrm{k}) \\
\mathrm{K} \quad= & 10(\log 12 \mathrm{H}-(\mathrm{V} \times 5,75 \mathrm{U} *))
\end{aligned}
$$

Dimana :

$$
\begin{array}{ll}
\mathrm{R} & =\text { Jari }- \text { jari Hidroulis } \\
\mathrm{D} 90 & =\text { Diameter butiran } \\
\mathrm{g} & =\text { Gravitasi } \\
\mathrm{l} & =\text { Kemiringan dasar sungai }
\end{array}
$$

2. Meyer - Peter dan Muller (1948)

$$
\begin{array}{ll}
\mathrm{Qb} & =\phi(g \cdot \Delta \cdot \mathrm{D} 503) 1 / 2 \\
\phi & =\left(4 \Psi^{\prime}-0.188\right) 3 / 2 \\
\Psi & =\mu \cdot \tau /(\Delta \cdot \rho W \cdot \mathrm{G} \cdot \mathrm{D} 50) \\
\tau & =\rho \mathrm{W} \cdot \mathrm{g} \cdot \mathrm{R} \cdot \mathrm{I} \\
\mu & =\left(\mathrm{C} / \mathrm{C}^{\prime}\right) 3 / 2 \\
\mathrm{C}^{\prime} & =18 \log (12 \mathrm{R} / \mathrm{D} 90)
\end{array}
$$

3. Formula Einstein

Einstein menetapkan persamaan muatan dasar sebagai persamaan yang meng 
hubungkan material dasar dengan pengaliran setempat (local flow). Per samaan itu menggambarkan keadaan seimbang daripada pertukaran butiran dasar antara lapisan dasar (bed layer) dan dasarnya. Einstein menggunakan $D=$ D35 untuk parameter angkutan, sedangkan untuk kekasaran digunakan D = D65. Hubungan antara kemungkinan butiran akan terangkut dengan intensitas ang kutan dasar dijabarkan sebagai berikut :

$$
\begin{aligned}
& \mathrm{Qb}=(\phi(\mathrm{g} \cdot \Delta . \mathrm{D} 353) 1 / 2) \cdot \mathrm{B} \\
& \phi \quad=0.044638+\left(0.36249 . \Psi^{\prime}\right)- \\
& (0.226795 . \Psi 2)+(0.036 . \Psi 3) \\
& \Psi=(\mu, \mathrm{R} . \mathrm{I}) /(\Delta . \mathrm{D} 35) \\
& \tau=\rho W . g . R . I \\
& \mu=\left(C / C^{\prime}\right) 3 / 2 \\
& C^{\prime}=18 \log (12 R / D 65) \\
& \mathrm{C}=\mathrm{V} /(\mathrm{R} . \mathrm{I}) 1 / 2 \\
& \mathrm{~A}=\text { Luas penampang basah ( } \mathrm{m} 2) \\
& P=\operatorname{Keliling} \text { basah }(\mathrm{m}) \\
& R=\text { Jari - jari hidroulis (A/ P) } \\
& \mathrm{V}=\operatorname{Kecepatan}(\mathrm{m} / \mathrm{dt}) \\
& \mathrm{Q}=\text { Debit }(\mathrm{m} 3 / \mathrm{dt}) \rightarrow \mathrm{V} \text {. A }
\end{aligned}
$$

a. Muatan Layang ( Suspended Load Transport )

Muatan layang (suspended load) yaitu partikel yang bergerak dalam pusaran aliran yang cenderung terus menerus melayang bersama aliran. Ukuran par tikelnya lebih kecil dari 0,1 $\mathrm{mm}$.

\section{Metode USBR}

Muatan layang (suspended load) dapat juga dihitung dengan menggunakan metode USBR (United State Beureu Reclamation) dimana untuk menghitung angkutan muatan layang. diperlukan pengukuran debit air (Qw) dalam $\mathrm{m} 3 /$ det, yang dikombinasikan dengan konsentrasi sedimen (C) dalam $\mathrm{mg} / \mathrm{lt}$, yang menghasilkan debit sedimen dalam ton/hari dihitung dengan persamaan (Strand, 1982:7)

Qs $=0,0864$ C. Qw

Dari perhitungan, dibuat lengkung aliran sedimen yang merupakan garis regresi antara angkutan sedimen dan debit air dengan persamaan:

Qs $=\mathrm{a} . \mathrm{Qwb}$

Dimana :

Qs = Beban layang (ton/ hari)

c $=$ Konsentrasi sedimen $(\mathrm{mg} / \mathrm{lt})$

Qw $=$ Debit sungai $(\mathrm{m} 3 /$ det $)$

$\mathrm{a}, \mathrm{b}=$ Konstanta

b. Total Muatan (Total Lod)

1. Englund dan Hansen

- $\mathrm{Qb}=\phi . I(\mathrm{~m} 3 / \mathrm{dt} / \mathrm{m})$

- $\phi \quad=0,1 .(1 / f) \cdot \Psi 2 \cdot 5$

- $\mathrm{W}=(\mathrm{R} . \mathrm{I}) /(\Delta . \mathrm{D} 50)$

- $f \quad=(2 . g) / C 2$

- $\mathrm{C}=\mathrm{V} /(\mathrm{R} . \mathrm{I}) 1 / 2$

- $\mathrm{A}=$ Luas penampang basah $(\mathrm{m} 2$

- $\mathrm{P}=$ Keliling basah $(\mathrm{m})$

$-\mathrm{R}=$ J ari - jari hidroulis (A/P)

- $\mathrm{V}=\operatorname{Kecepatan}(\mathrm{m} / \mathrm{dt})$

- $\mathrm{Q}=$ Debit $(\mathrm{m} 3 / \mathrm{dt}) \rightarrow \mathrm{V}$. A

Dimana :

$R \quad=$ Jari - jari Hidroulis

D50 = Diameter butiran

g $=$ Gravitasi

I = Kemiringan dasar sungai

\section{METODOLOGI}

Langkah - langkah yang dilakukan dalam studi ini adalah sebagai berikut:

- Melakukan pengukuran debit secara langsung dilapangan dengan mengukur luas penampang basah dan kecepatan diukur dengan current meter

- Melakukan pengambilan sample sedimen

- Menganalisa butiran sediment di laboratorium

- Melakukan perhitungan angkutan sediment meliputi : Suspended load, Bed load, dan Total load. 


\section{ANALISA}

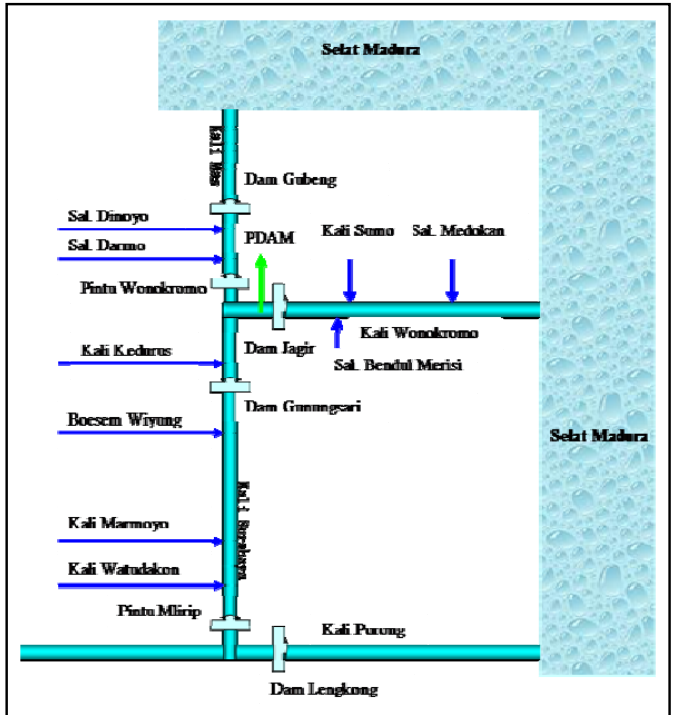

Gamb. 2 - Skema 1 Permodelan Sistem Kali Surabaya, Kali Mas dan kali Wonokromo

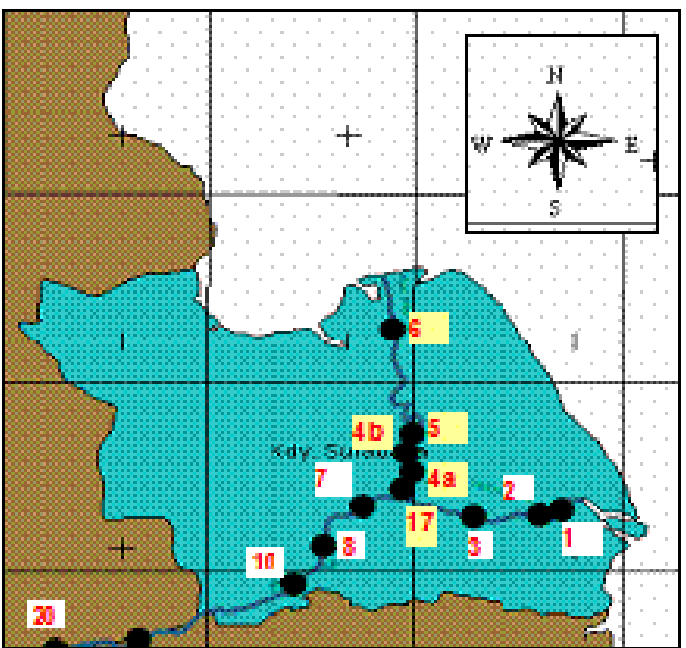

Gamb. 3 - Skema 2 Permodelan Sistem Kali Surabaya, Kali Mas dan kali Wonokromo

Tabel 1 - Titik Pengukuran Debit Kali Mas

\begin{tabular}{|c|l|c|c|}
\hline \multicolumn{3}{|c|}{ Tanggal : 26 Juli 2006 } \\
\cline { 3 - 4 } $\begin{array}{c}\text { No } \\
\text { Lokasi }\end{array}$ & \multicolumn{1}{|c|}{ Lokasi / Waktu } & KIRI & KOORDINAT UTM \\
\hline \multirow{2}{*}{5} & K. Mas & $\mathrm{X}-0692607$ & $\mathrm{X}-0692822$ \\
& Jemb.Yos Sudarso & $\mathrm{Y}-9196868$ & $\mathrm{Y}-9196882$ \\
\multirow{5}{*}{6} & Jam: 12.50 & $\mathrm{X}-0691934$ & $\mathrm{X}-0691894$ \\
& K. Mas & $\mathrm{Y}-9201158$ & $\mathrm{Y}-9201156$ \\
& Jemb. Petekan & & \\
\cline { 2 - 4 } & Jam : 14.35 & &
\end{tabular}

Sumber : Hasil Pengamatan
Tabel.2 - Ringkasan Hasil Pengamatan konsentrasi sedimen melayang

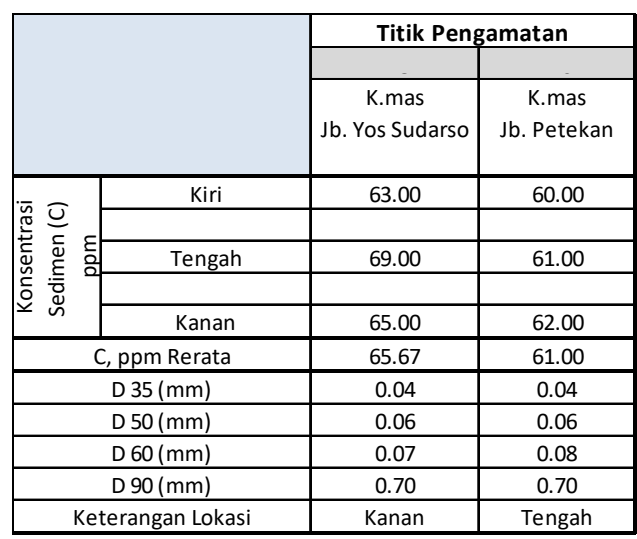

Tabel 3 - Diskripsi material sedimen dan nilai Spesific Gravity (GS)

\begin{tabular}{|c|c|c|c|c|c|c|c|}
\hline \multirow[b]{2}{*}{ No } & \multirow{2}{*}{\multicolumn{2}{|c|}{ LOKASI }} & \multicolumn{4}{|c|}{ DISCRIPTION } & \multirow[b]{2}{*}{ GS } \\
\hline & & & GRAVEL & SAND & SILT & CLAY & \\
\hline \multirow[t]{6}{*}{1} & River & Kali Mas & & & & & \\
\hline & Location & $\mathrm{Jb}$.Petekan & & & & & \\
\hline & & T.6 (kanan) & $0 \%$ & $51 \%$ & $35 \%$ & $14 \%$ & 2,6643 \\
\hline & & T.6 (kiri) & $0 \%$ & $46 \%$ & $32 \%$ & $22 \%$ & 2,6675 \\
\hline & & T.6 (tengah) & $0 \%$ & $42 \%$ & $36 \%$ & $22 \%$ & 2,6645 \\
\hline & & & & & & & \\
\hline \multirow[t]{5}{*}{2} & River & Kali Mas & & & & & \\
\hline & Location & Jb.Yos Sudarso & & & & & \\
\hline & & T.5 (kanan) & $0 \%$ & $37 \%$ & $41 \%$ & $22 \%$ & 2,6767 \\
\hline & & T.5 (kiri) & $0 \%$ & $32 \%$ & $46 \%$ & $22 \%$ & 2,6763 \\
\hline & & & & & & & \\
\hline
\end{tabular}

\subsection{Perhitungan Angkutan Sedimen Hasil Pengamatan}

a. Perhitungan angkutan sedimen layang (suspended load).

Seperti telah dijelaskan bahwa perhitungan angkutan sedimen layang dapat ditentukan berdasarkan hasil pengukuran langsung dari debit air dan konsentrasi sedimen. Dimana perumusannya adalah : Qs $=0,0864 \times$ Qw $\times$ C ton/ hari dimana :

Qs = debit sedimen (sedimen transport) ton/hari

Qw = debit aliran (m3/ det)

$\mathrm{C}=$ konsentrasi sedimen $(\mathrm{mg} / \mathrm{lt})$

$\mathrm{K}=0,0864=$ faktor peruba han unit.

Hasil perhitungan sedimen layang untuk lokasi pengamatan adalah sebagai berikut : 
Tabel.4- Perhitungan Suspended Load Kali Mas dengan Metode USBR

\begin{tabular}{|c|c|c|c|}
\hline & \multicolumn{2}{|c|}{ Titik Pengamatan } \\
\hline & & $\begin{array}{c}\text { K.mas } \\
\text { Jb. Yos Sudarso }\end{array}$ & $\begin{array}{c}\text { K.mas } \\
\text { Jb. Petekan }\end{array}$ \\
\hline $\mathrm{B}$ & $(\mathrm{m})$ & 16.00 & 15.00 \\
\hline $\mathrm{H}$ & $(\mathrm{m})$ & 1.33 & 1.95 \\
\hline $\mathrm{A}$ & $(\mathrm{m} 2)$ & 17.70 & 62.70 \\
\hline $\mathrm{P}$ & $(\mathrm{m})$ & 16.49 & 36.64 \\
\hline $\mathrm{R}$ & $(\mathrm{m})$ & 1.07 & 1.71 \\
\hline $\mathrm{V}$ & $(\mathrm{m} / \mathrm{dt})$ & 0.50 & 0.47 \\
\hline Qw & $\mathrm{m} 3 / \mathrm{dt}$ & 8.79 & 29.35 \\
\hline Qs & ton/hari & 49.88 & 154.70 \\
\hline Qs & $\mathrm{m} 3 /$ hari & 18.63 & 58.05 \\
\hline
\end{tabular}

b. Perhitungan angkutan sedimen dasar (bed load).

Dengan menggunakan persamaan dari :

1. Meyer Peter Muler.

2. Einstein

3. Frijlink

Dimana perhitungan tersebut meng gunakan data distribusi ukuran butir endapan dasar dan hidrolis sungai.

Hasil perhitungan sedimen dasar berdasarkan data pengamatan di masing-masing titik pengambilan adalah sebagai berikut :

Tabel.5 - Data Konsentrasi Sedimen dan Analisis D 35, D 50, D 60 dan D 90

\begin{tabular}{|c|c|c|c|}
\hline & \multicolumn{2}{|c|}{ Titik Pengamatan } \\
\hline & & $\begin{array}{c}\text { K.mas } \\
\mathrm{Jb} \text {. Yos Sudarso }\end{array}$ & $\begin{array}{c}\text { K.mas } \\
\text { Jb. Petekan }\end{array}$ \\
\hline \multirow{4}{*}{ 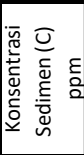 } & Kiri & 63.00 & 60.00 \\
\hline & Trnar & 6900 & 6100 \\
\hline & & & \\
\hline & Kanan & 65.00 & 62.00 \\
\hline \multicolumn{2}{|r|}{ C, ppm Rerata } & 65.67 & 61.00 \\
\hline \multicolumn{2}{|r|}{ D $35(\mathrm{~mm})$} & 0.04 & 0.04 \\
\hline \multicolumn{2}{|r|}{$\mathrm{D} 50(\mathrm{~mm})$} & 0.06 & 0.06 \\
\hline \multicolumn{2}{|r|}{$\mathrm{D} 60(\mathrm{~mm})$} & 0.07 & 0.08 \\
\hline \multicolumn{2}{|r|}{ D $90(\mathrm{~mm})$} & 0.70 & 0.70 \\
\hline \multicolumn{2}{|c|}{ Keterangan Lokasi } & Kanan & Tengah \\
\hline \multicolumn{2}{|c|}{ Slope rata - rata } & 0.001 & 0.001 \\
\hline \multicolumn{2}{|c|}{ Spes.Gravity (Gs) } & 2.68 & 2.67 \\
\hline \multicolumn{2}{|c|}{ Rap. Massa sed. ( $\rho s)$} & 2.68 & 2.67 \\
\hline \multicolumn{2}{|c|}{$\Delta$} & 0.63 & 0.62 \\
\hline
\end{tabular}

Keterangan :

$\rho \mathrm{w}$ (Rapat massa air) $=1.00 \mathrm{ton} / \mathrm{m} 3$

$\rho s$ (Rapat massa sedimen) $=\mathrm{Gs} . \rho \mathrm{W}$
Tabel.6 - Perhitungan Bed Load Kali Mas Metode Meyer Peter and Muller ( MPM)

\begin{tabular}{|c|c|c|c|}
\hline & \multicolumn{2}{|c|}{ Titik Pengamatan } \\
\hline & & $\begin{array}{c}\text { K.mas } \\
\text { Jb. Yos Sudarso }\end{array}$ & $\begin{array}{c}\text { K.mas } \\
\text { Jb. Petekan }\end{array}$ \\
\hline $\mathrm{B}$ & $(\mathrm{m})$ & 16.00 & 36.00 \\
\hline $\mathrm{H}$ & $(\mathrm{m})$ & 1.33 & 1.95 \\
\hline$A$ & $\left(\mathrm{~m}^{2}\right)$ & 17.70 & 62.70 \\
\hline $\mathrm{P}$ & $(\mathrm{m})$ & 16.49 & 36.64 \\
\hline $\mathrm{R}$ & $(\mathrm{m})$ & 1.07 & 1.71 \\
\hline $\mathrm{V}$ & $(\mathrm{m} / \mathrm{dt})$ & 0.50 & 0.47 \\
\hline Qw & $\left(\mathrm{m}^{3} / \mathrm{dt}\right)$ & 8.79 & 29.40 \\
\hline $\mathrm{C}$ & $\left(\mathrm{m}^{0.5} / \mathrm{dt}\right)$ & 60.82 & 45.40 \\
\hline $\mathrm{C}^{\prime}$ & $\left(\mathrm{m}^{0.5} / \mathrm{dt}\right)$ & 76.77 & 80.41 \\
\hline $\boldsymbol{\mu}$ & & 0.71 & 0.42 \\
\hline$\tau$ & & 0.001 & 0.001 \\
\hline$\Psi$ & & 1.34 & 1.20 \\
\hline$\Phi$ & & 11.77 & 9.95 \\
\hline \multirow{3}{*}{$\begin{array}{l}\text { Qb (Debit } \\
\text { Bed Load) }\end{array}$} & $\mathrm{m} 3 / \mathrm{dt}$ & 0.000196 & 0.000412 \\
\hline & $\mathrm{m} 3 / \mathrm{hr}$ & 16.90 & 35.60 \\
\hline & ton $/ \mathrm{hr}$ & 45.25 & 94.87 \\
\hline
\end{tabular}

Tabel. 7 - Perhitungan Bed Load Kali Mas Metode Einstein

\begin{tabular}{|c|c|c|c|}
\hline & \multicolumn{2}{|c|}{ Titik Pengamatan } \\
\hline & & $\begin{array}{c}\text { K.mas } \\
\text { Jb. Yos Sudarso }\end{array}$ & $\begin{array}{l}\text { K.mas } \\
\text { Jb. Petekan }\end{array}$ \\
\hline B & $(\mathrm{m})$ & 16.00 & 36.00 \\
\hline $\mathrm{H}$ & $(\mathrm{m})$ & 1.33 & 1.95 \\
\hline A & $\left(\mathrm{m}^{2}\right)$ & 17.70 & 62.70 \\
\hline $\mathrm{P}$ & $(\mathrm{m})$ & 16.49 & 36.64 \\
\hline $\mathrm{R}$ & $(\mathrm{m})$ & 1.07 & 1.71 \\
\hline $\mathrm{V}$ & $(\mathrm{m} / \mathrm{dt})$ & 0.50 & 0.47 \\
\hline Qw & $\left(\mathrm{m}^{3} / \mathrm{dt}\right)$ & 8.79 & 29.40 \\
\hline $\mathrm{C}$ & $\left(\mathrm{m}^{0.5} / \mathrm{dt}\right)$ & 60.82 & 45.40 \\
\hline$C^{\prime}$ & $\left(\mathrm{m}^{0.5} / \mathrm{dt}\right)$ & 94.77 & 97.37 \\
\hline$\mu$ & & 0.80 & 0.68 \\
\hline$\Psi$ & & 2.13 & 2.91 \\
\hline$\Phi$ & & 0.14 & 0.07 \\
\hline & $\mathrm{m} 3 / \mathrm{dt}$ & 0.000001 & 0.000001 \\
\hline Ro (Debit & $\mathrm{m} 3 / \mathrm{hr}$ & 0.12 & 0.13 \\
\hline & ton $/ \mathrm{hr}$ & 0.31 & 0.34 \\
\hline
\end{tabular}


Tabel. 8 - Perhitungan Bed Load Kali Mas Metode Frijlink

\begin{tabular}{|c|c|c|c|}
\hline & \multicolumn{2}{|c|}{ Titik Pengamatan } \\
\hline & & $\begin{array}{c}\text { K.mas } \\
\text { Jb. Yos Sudarso }\end{array}$ & $\begin{array}{c}\text { K.mas } \\
\text { Jb. Petekan }\end{array}$ \\
\hline $\mathrm{B}$ & $(\mathrm{m})$ & 16.00 & 36.00 \\
\hline $\mathrm{H}$ & $(\mathrm{m})$ & 1.33 & 1.95 \\
\hline$A$ & $\left(m^{2}\right)$ & 17.70 & 62.70 \\
\hline $\mathrm{P}$ & $(\mathrm{m})$ & 16.49 & 36.64 \\
\hline $\mathrm{R}$ & $(\mathrm{m})$ & 1.07 & 1.71 \\
\hline V & $(\mathrm{m} / \mathrm{dt})$ & 0.50 & 0.47 \\
\hline Qw & $\left(\mathrm{m}^{3} / \mathrm{dt}\right)$ & 8.79 & 29.40 \\
\hline $\mathrm{U}^{*}$ & & 0.0256 & 0.0323 \\
\hline $\mathrm{k}$ & $(\mathrm{m})$ & 0.0067 & 0.0705 \\
\hline $\mathrm{C}$ & & 60.78 & 45.38 \\
\hline $\mathrm{C}_{\mathrm{d} 90}$ & & 78.46 & 81.43 \\
\hline$\mu$ & & 0.68 & 0.42 \\
\hline$\Psi$ & & 0.77 & 0.85 \\
\hline$\Phi$ & & 3.40 & 3.70 \\
\hline \multirow{3}{*}{$\begin{array}{l}\text { Qb (Debit } \\
\text { Bed Load) }\end{array}$} & $\mathrm{m} 3 / \mathrm{dt}$ & 0.000064 & 0.000017 \\
\hline & $\mathrm{m} 3 / \mathrm{hr}$ & 5.56 & 14.38 \\
\hline & ton/hr & 14.88 & 38.33 \\
\hline
\end{tabular}

\subsection{Perhitungan angkutan sedimen total (total load).}

Untuk menghitung angkutan sedimen total bisa digunakan metode penjumlahan antara sedimen layang (suspended load) dengan sedimen dasar (bed load) atau

$\mathrm{Qt}=\mathrm{Q} s+\mathrm{Qb}$

Namun demikian ada beberapa formula empiris yang juga dapat digunakan menghitung laju sedimen total, dimana hasil perhitungan sudah merupakan laju angkutan sedimen total (Qt), diantaranya:

a. Engelund and Hansen

b. Kikawa - Ashida

Hasil perhitungan sedimen total di masing-masing titik pengambilan adalah sebagai berikut :
Tabel. 9 - Perhitungan Total Load Metode Engelund dan Hansen

\begin{tabular}{|c|c|c|c|}
\hline & \multicolumn{2}{|c|}{ Titik Pengamatan } \\
\hline & & $\begin{array}{c}\text { K.mas } \\
\text { Jb. Yos Sudarso }\end{array}$ & $\begin{array}{c}\text { K.mas } \\
\text { Jb. Petekan }\end{array}$ \\
\hline $\mathrm{B}$ & $(\mathrm{m})$ & 16.00 & 36.00 \\
\hline $\mathrm{H}$ & $(\mathrm{m})$ & 1.33 & 1.95 \\
\hline $\mathrm{A}$ & $\left(\mathrm{m}^{2}\right)$ & 17.70 & 62.70 \\
\hline $\mathrm{P}$ & $(\mathrm{m})$ & 16.49 & 36.64 \\
\hline$R$ & $(\mathrm{~m})$ & 1.07 & 1.71 \\
\hline $\mathrm{V}$ & $(\mathrm{m} / \mathrm{dt})$ & 0.50 & 0.47 \\
\hline Qw & $\left(\mathrm{m}^{3} / \mathrm{dt}\right)$ & 8.79 & 29.40 \\
\hline $\mathrm{C}$ & & 15.16 & 11.32 \\
\hline$f$ & & 0.09 & 0.15 \\
\hline$\Psi$ & & 30.60 & 45.65 \\
\hline$\Phi$ & & 6064.69 & 9190.66 \\
\hline & $\mathrm{m} 3 / \mathrm{dt}$ & 0.00630 & 0.01057 \\
\hline $\mathrm{Q}$ (total) & $\mathrm{m} 3 / \mathrm{hr}$ & 544.35 & 913.65 \\
\hline & ton/hr & 1457.24 & 2434.88 \\
\hline
\end{tabular}

\section{KESIMPULAN}

- Perhitungan Sedimentasi di Kali Mas pada titik pengamatan Jembatan Yos Sudarso dan J embatan Petekan

- Besarnya Debit yang terukur di J embatan Yoa Sudarso $=8.75 \mathrm{~m} 3 / \mathrm{dt}$ dan di J embatan Petekan $=29.35$ $\mathrm{m} 3 / \mathrm{dt}$.

- Perhitungan Suspended Load di J embatan Yoa Sudarso $=18 \mathrm{~m} 3 /$ hari dan di J embatan Petekan $=58.05$ $\mathrm{m} 3$ / hari.

- Perhitungan Bed Load di Jembatan Yoa Sudarso $=16.90 \mathrm{~m} 3 /$ hari dan di J embatan Petekan $=35.60 \mathrm{~m} 3 /$ hari.

- Perhitungan Total Sedimen (Total Load ) di Jembatan Yos Sudarso = $544.35 \mathrm{~m} 3 /$ hari dan di Jembatan Petekan $=913.65 \mathrm{m3} / \mathrm{dt}$.

\section{DAFTAR PUSTAKA}

- Unibraw 2006, Studi Sediment Transport Sistem Kali Surabaya, Kali Mas, dan Kali Wonokromo. Unibraw Malang.

- JICA. 1998. The Studi on Comrehensive Management Plan for The Water Resources of The Brantas 
River Basin in The Republic of Indonesia. Surabaya.

- Chow VT 1959, Open Channel Hydraulics Mc Graw Hill Kogakusha, LTD.

- Thorne CR 1987, Sediment Transport in Gravel - Bed Rivers. J ohn Wiley \& Son, New York.

- Meyer - Peter, E and Muller, R 1948, Formulas for Bed load Transport in Proc. 2nd Congr. IAHR Stockholm, Vol. 2, Paper. 2, PP : 39 - 64.

- Einstein, H. A. 1950, The Bed Load Function, for Sediment Transport in open channel flow. US. Dept. of Agric. Bull. 1026. 